\section{(6) OPEN ACCESS}

\title{
Effectiveness of chemical pleurodesis in spontaneous pneumothorax recurrence prevention: a systematic review
}

\author{
R J Hallifax, ${ }^{1}$ A Yousuf, ${ }^{1}$ H E Jones, ${ }^{2}$ J P Corcoran, ${ }^{1}$ I Psallidas, ${ }^{1}$ N M Rahman ${ }^{1}$
}

10xford Centre for Respiratory Medicine, Oxford University Hospitals NHS Trust, Oxford, UK ${ }^{2}$ Faculty of Health Sciences, School of Social and Community Medicine, University of Bristol, Bristol, UK

\section{Correspondence to} Dr Rob J Hallifax, Oxford Respiratory Trials Unit, University of Oxford, Churchill Hospital, Oxford OX3 7LJ, UK: robhallifax@yahoo.com

Received 21 October 2015 Revised 2 August 2016 Accepted 15 August 2016 Published Online First 1 November 2016
ABSTRACT

Objectives Spontaneous pneumothorax is a common pathology. International guidelines suggest pleurodesis for non-resolving air leak or recurrence prevention at second occurrence. This study comprehensively reviews the existing literature regarding chemical pleurodesis efficacy.

Design We systematically reviewed the literature to identify relevant randomised controlled trials (RCTs), case-control studies and case series. We described the findings of these studies and tabulated relative recurrence rates or ORs (in studies with control groups). Meta-analysis was not performed due to substantial clinical heterogeneity.

Results of 560 abstracts identified by our search strategy, 50 were included in our systematic review following screening. Recurrence rates in patients with chest tube drainage only were between $26.1 \%$ and $50.1 \%$. Thoracoscopic talc poudrage (four studies $(n=249))$ provided recurrence rates of between $2.5 \%$ and $10.2 \%$ with the only RCT suggesting an OR of 0.10 compared with drainage alone. In comparison, talc administration during video-assisted thoracic surgery (VATS) from eight studies ( $n=2324)$ recurrence was between $0.0 \%$ and $3.2 \%$, but the RCT did not demonstrate a significant difference compared with bleb/ bullectomy alone. Minocycline appears similarly effective post-VATS (recurrence rates $0.0-2.9 \%$ ). Prolonged air leak and recurrence prevention using tetracycline via chest drain $(n=726)$ is likely to provide recurrence rates between $13.0 \%$ and $33.3 \%$ and autologous blood patch pleurodesis $(n=270)$ between $15.6 \%$ and $18.2 \%$. Conclusions Chemical pleurodesis postsurgical treatment or via thoracoscopy appears to be most effective. Evidence for definitive success rates of each agent is limited by the small number of randomised trials or other comparative studies.

\section{INTRODUCTION}

\section{SLinked}

- http://dx.doi.org/10.1136/ thoraxjnl-2017-211007

CrossMark

To cite: Hallifax RJ, Yousuf $A$ Jones HE, et al. Thorax 2017;72:1121-1131.
Pneumothorax, air in the pleural space, is a common pathology. Primary spontaneous pneumothorax (PSP) refers to patients with no underlying lung disease, while those with established lung pathology are classified as secondary spontaneous pneumothorax (SSP). The incidence of spontaneous pneumothoraces based on populations in the USA $^{1}$ and Sweden $^{2}$ is reported as $18-24$ per 100000 cases per annum for men and 1.2-6 per 100000 for women. PSP has a reported incidence of 7.4-18 cases (age-adjusted incidence) and 1.2-6 cases per 100000 population per year for males

\section{Key messages}

What is the key question?

- How effective are chemical pleurodesis agents at recurrence prevention in spontaneous pneumothorax?

\section{What is the bottom line?}

- Talc poudrage at thoracoscopy and talc or minocycline pleurodesis as an adjunct to surgery provide low recurrence rates. Less invasive options include pleurodesis using tetracycline or 'blood patch' via chest drain.

\section{Why read on?}

- This review is the first to systematically assess the evidence for pleurodesis efficacy in recurrence prevention for all chemical pleurodesis agents in cases of spontaneous pneumothorax in both 'medical' pleurodesis (ie, no intervention on the lung) and as an adjunct to surgical procedures.

and females, respectively. ${ }^{1}{ }^{2}$ UK data on hospital admission rates (for PSP and SSP combined) demonstrate an incidence of 16.7 cases per 100000 for men and 5.8 cases per 100000 for women, with corresponding mortality rates of 1.26 per million and 0.62 per million per annum. ${ }^{3}$ More recent data from France have demonstrated a similar rate of 22.7 cases per 100000 population. $^{4}$

Recurrence rates for spontaneous pneumothorax (SP) are quoted as approximately $30 \%$, with individual studies reporting a recurrence rate of between $17 \%$ and $49 \% .^{5-12}$ Initial treatment regimens and strategies for recurrence prevention remain controversial. Recurrence prevention involves an attempt at pleurodesis (permanent apposition of the visceral and parietal pleura to seal the pleural space), which can be chemical (or 'medical') using an agent introduced into the pleural cavity or surgical by apical pleurectomy or pleural abrasion. International guidelines currently recommend pleurodesis for non-resolving pneumothoraces acutely or electively to prevent recurrence after a second occurrence of pneumothorax. However, guidelines do not specify the optimal pleurodesis approach or agent for chemical pleurodesis. ${ }^{13-15}$ 
For PSP, the American College of Chest Physicians (ACCP) Delphi consensus statement ${ }^{13}$ recommends surgical pleurodesis via thoracoscopy (including bullectomy) for ongoing air leak ( $>4$ days) or recurrence prevention at second occurrence. In this statement, there was no consensus on the utility of additional talc poudrage at surgical procedure for patients with PSP. Chemical pleurodesis via a chest drain was thought to be acceptable for patients in whom surgery was contraindicated or patients who refused an operative procedure. The statement recommends doxycycline or talc as the preferred agent in cases where chemical pleurodesis is conducted. ${ }^{13}$ For SSP, this statement suggests intervention to prevent pneumothorax recurrence at first occurrence (in contrast to PSP), with the surgical approach as first choice and chemical pleurodesis as an option for the high-risk patient or those declining surgery. The ACCP guidance was published in 2001, and therefore may no longer be up to date.

The British Thoracic Society (BTS, 2010) ${ }^{14}$ and the Belgian Society of Pulmonology (BSP, 2005) ${ }^{15}$ guidelines for PSP and SSP both recommend surgical pleurodesis for ongoing air leak acutely and recurrence prevention at second occurrence. They state that "with the advent of VATS for pneumothorax repair and recurrence prevention, the use of surgical chemical pleurodesis has declined significantly". ${ }^{14}$ Medical chemical pleurodesis is recommended in patients unwilling or unable to undergo surgery, and is therefore more likely to be applicable to patients with SSP. The BTS makes reference to tetracycline as the previous first-line agent for PSP and SSP, but with decline in usage through difficulties in supply in favour of graded talc, with passing mention of minocycline and doxycycline efficacy in animal models. ${ }^{14}$ The BSP does not comment on pleurodesis agent.

This study aimed to systematically review the existing literature regarding the efficacy of chemical pleurodesis for recurrence prevention in pneumothorax.

\section{METHODS}

\section{Eligibility criteria}

We systematically reviewed the literature to identify relevant randomised controlled trials (RCTs), case-control studies and case series (without comparator groups) of $\geq 10$ cases. Case series were specifically included because the authors were aware of a dearth of trials data in this area.

Studies were considered eligible for inclusion with the following criteria: adult patients ( $\geq 18$ years old) with spontaneous (primary and secondary) pneumothorax, undergoing pleurodesis at first occurrence or subsequent recurrence, or for the treatment of persistent air leak, by instillation via chest tube or in addition to surgical procedure; interventions consisting of chemical pleurodesis with any agent. Comparators included were any of chest tube drainage alone (no pleurodesis), other pleurodesis agent and surgical procedures (eg, mechanical abrasion, bleb/bullectomy, pleurectomy). The outcome was pneumothorax recurrence rate (ideally, after at least 1 year of follow-up).

Exclusions consisted of the following: animal or paediatric studies, non-primary studies (ie, letters, editorials and review articles), pleurodesis for malignant pleural effusion, surgical pleurodesis only (with no sclerosant inserted), pleurodesis for postoperative air leak, insufficient data on agent or technique used, inadequate follow-up period (ie, $<3$ months) and case series with $<10$ cases.

Papers were also excluded if the authors were unable to obtain a translation (if not published in English) or unable to obtain the paper online or via our hosts' extensive library access collections.

\section{Search strategy}

Literature searches of multiple databases (including PubMed, Embase, Medline, Web of Science, Cochrane Library) were performed up to and including June 2016. Results were not restricted by year of publication. Combinations of search terms were used and adapted for each database as appropriate, including "pleurodesis", "spontaneous", "pneumothor*”, “chemical", "talc", "tetracycline", "minocycline", "iodopovidine" and "blood". In addition to electronic database searches, reference lists, relevant textbooks and review articles were hand-searched and back-referenced (ie, reference lists of review articles examined for additional studies not appearing in initial searches). Abstracts were independently reviewed for relevance by two authors (RJH and AY). Any discrepancies were resolved by discussion (with JPC and IP) with a low threshold for review of the full article. Relevant full journal articles were subsequently assessed again for eligibility.

\section{Data extraction}

Data were extracted from the full articles separately by two authors using a prespecified extraction form (Microsoft Excel 2010, Microsoft, USA). Extracted information included lead author, year, geographical area, nature of pneumothorax (primary or secondary, where available), number of participants, intervention agent(s), control/comparator measures, recurrence rate for each arm, follow-up timescale (mean or median when described), study type and quality. In those with mixed populations (eg, including patients with pleural effusions or postoperative air leak), only data pertaining to SP were extracted. Where available, data on number of episodes of pneumothorax (rather than number of patients) were extracted. Early pleurodesis failures that required further procedure or surgical referral were included in the calculated recurrences rates.

\section{Quality and risk of bias assessment}

Risk of bias of the included RCTs was assessed using the Cochrane Risk of Bias tool. ${ }^{16}$ This tool addresses seven domains: sequence generation, allocation concealment, blinding of participants and personnel, blinding of outcome assessment, incomplete outcome data, selective outcome reporting and 'other issues'. We did not formally assess risk of bias in casecontrol studies or case series.

\section{Data analysis}

Given the considerable heterogeneity in study design, pleurodesis agents, control groups and outcomes across identified studies, formal data synthesis via meta-analysis was not conducted as any results would not be clinically meaningful. ORs with $95 \%$ CIs were calculated where possible as a measure of the effectiveness in reducing pneumothorax recurrence relative to a control. For studies with no comparison group, we display simply estimates of the pneumothorax recurrence rate in the single arm, with a 95\% CI (calculated on the log scale). When zero recurrences occurred, we approximated the upper limit of the CI for recurrence rate by $3 / \mathrm{n}^{16}$ (Section 16.9.4) and applied the standard approximation of adding 0.5 to all cell counts before calculating ORs and their CIs ${ }^{16}$ (Section 16.9.2).

\section{RESULTS}

After deduplication of search results, 560 abstracts were reviewed (see figure 1). In total, 468 were excluded as not eligible for our 


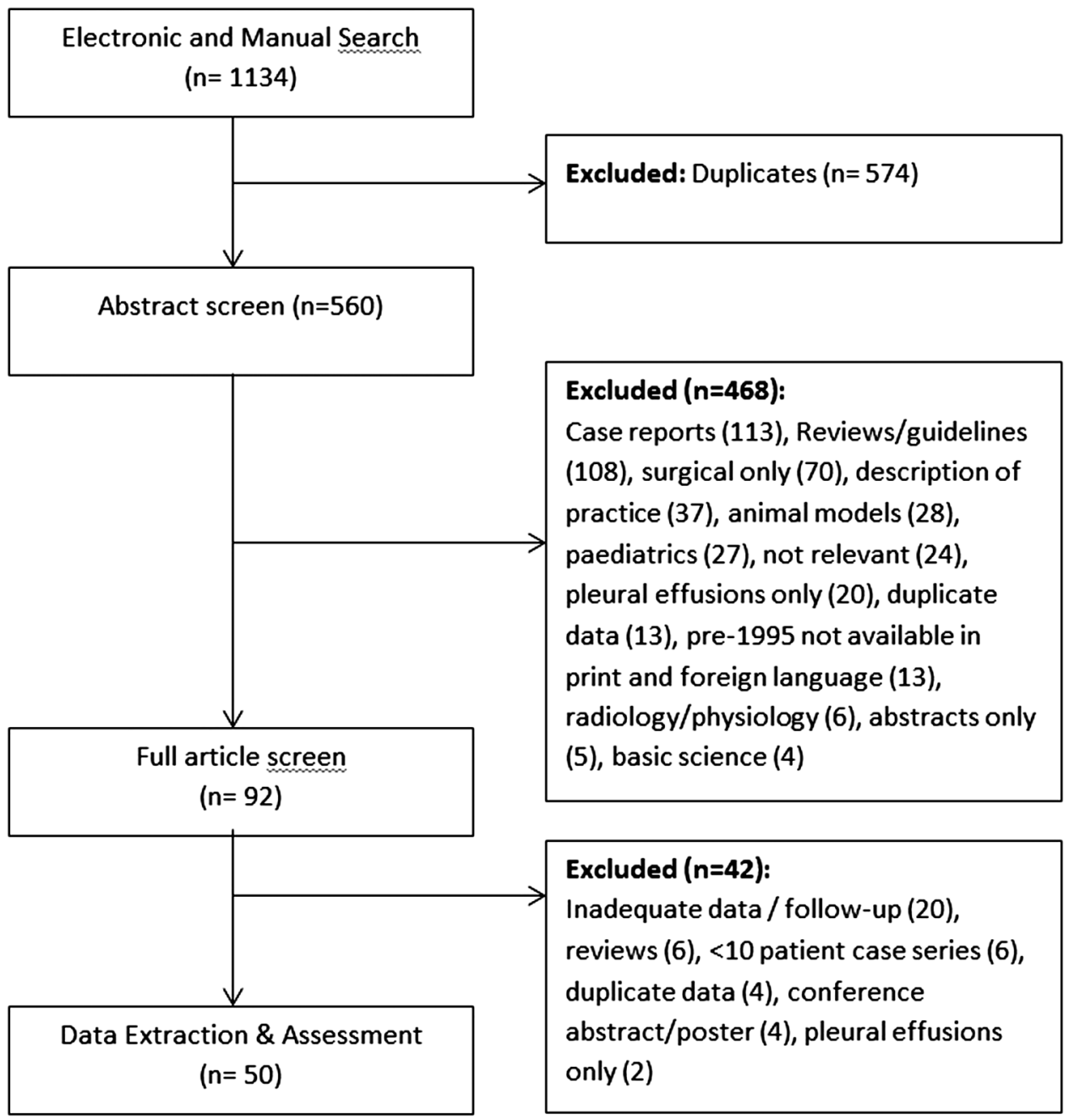

Figure 1 Preferred reporting items for systematic reviews and meta-analyses (PRISMA) flow diagram of study selection.

review at this stage (case reports, reviews, surgical series or description of practice, animal models, paediatric cases, pleurodesis for pleural effusions only, duplicate data or basic science articles) and we were unfortunately unable to obtain full-text copies of 13 papers published prior to 1995 (in foreign language). Of the remaining 92 potentially eligible papers, an additional 42 studies were identified as not being eligible for data extraction (20 within inadequate data or no long-term follow-up data, 6 reviews, 6 with $<10$ cases, 4 were duplicate data from other publications, 4 conference posters or abstracts only and 2 only related to pleural effusion management) when full texts were screened. Hence, 50 relevant studies were identified. We summarise results from 50 studies.

These 50 studies varied in size, quality and study design: 9 RCTs, 10 prospective case series (3 with non-randomised comparator groups) and 31 retrospective case series (10 with nonrandomised comparator groups). The indication for pleurodesis varied; $16(32 \%)$ studies stated an indication of pneumothorax recurrence or ongoing air leak, 7 (14\%) enrolled only those at first occurrence, $6(12 \%)$ assessed patients with ongoing air leak, $5(10 \%)$ studied recurrent pneumothorax only and 3 studies $(6 \%)$ enrolled a mixture of first occurrence, recurrent pneumothorax and ongoing leak or haemothorax. The remaining 13 studies (26\%) did not specify the indication for recurrence prevention precisely enough to categorise this further.
Assessment of bias of the RCTs showed a low risk of reporting, detection or attrition bias as the outcomes of pneumothorax recurrence were well reported and the loss to follow-up was low. The randomisation process was generally well described and adequate, with the exception of some of the older studies that did not describe the process ${ }^{6}{ }^{7}$ and a more recent study that appeared to be alternating treatment arms based upon trial number. ${ }^{17}$ None of the studies were blinded, some providing explanation of why this was not attempted: difficulties of matching colour of agent or that the expected pain associated with minocycline instillation would be likely to unmask the blinding.

\section{Talc}

Twenty-four studies used talc as a chemical pleurodesis agent. Twelve assessed the efficacy of talc poudrage for the treatment of PSP: four in which talc poudrage was performed at medical thoracoscopy with no associated intervention on the lung (table 1) and eight in which talc poudrage was administered post-video-assisted thoracoscopic surgery (VATS) with bleb electrocoagulation, bleb resection or apical bullectomy (table 2).

Of the four studies in which talc poudrage was performed without intervention on the lung (table 1), only one was an RCT. It demonstrated a lower recurrence rate among those receiving talc poudrage compared with those treated with drainage alone (talc $5.1 \%$ vs drainage $34.0 \%$, OR 0.10 , 95\% CI 0.03 


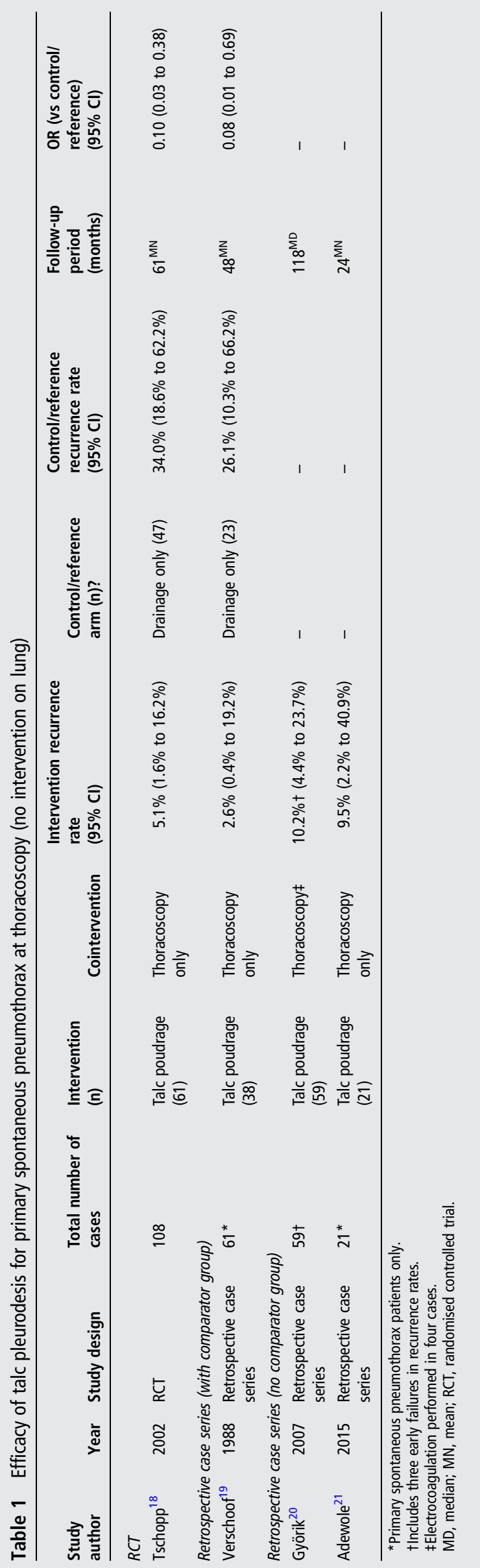

to 0.38$).{ }^{18} \mathrm{~A}$ case series study with a (non-randomised) control arm provided similar estimates: talc $2.6 \%$ versus drainage 26.1\%, OR 0.08 (95\% CI 0.01 to 0.69). ${ }^{19}$ Two case series, without comparators, estimated $10.2 \%$ recurrence in patients presenting with recurrent PSP or ongoing air leak (including early failures), ${ }^{20}$ and $9.5 \%$ in combination of first episode $(62 \%)$ and recurrent (38\%) PSPs. $^{21}$ All four studies had follow-up periods of at least 24 months (table 1).

In the eight surgical studies evaluating talc poudrage for PSP post-VATS with bleb electrocoagulation, bleb resection or apical bullectomy, the follow-up period was variable from 10 to 62 months (table 2). There was only one RCT, which was carried out in 141 patients undergoing VATS with bleb resection or electrocoagulation. The recurrence rate among patients receiving talc and dextrose was $2.4 \%$ compared with $6.0 \%$ in the control arm of surgery only. However, the CI for the OR was very wide, indicating that we cannot be confident about this finding: OR 0.38 (95\% CI 0.04 to 3.82$){ }^{22}$ Further, similar results were also seen by simply introducing dextrose without talc. $^{22}$ Observed recurrence rates across the other seven surgical studies were between $0.0 \%$ and $3.2 \% .^{23-29}$ Only two of these had (non-randomised) comparator groups, ${ }^{26} 29$ one of which provided statistical evidence for a reduced recurrence rate in those receiving talc compared with pleural abrasion: talc $1.5 \%$ versus pleural abrasion $4.0 \%$, OR 0.38 (95\% CI 0.15 to $0.97) .^{26}$

Indications for surgical intervention in these studies were recurrent PSP or ongoing air leak, ${ }^{24} 2528$ including first presentation in two studies, ${ }^{23} 29$ one solely treating first occurrence ${ }^{27}$ and two in which this aspect was not specified. ${ }^{22} 26$ The surgical procedures undertaken varied both within and across the studies. Some studies stated that bleb/apical electrocoagulation or resection was only performed if visible abnormalities were seen, ${ }^{23} 252829$ whereas others performed the procedure in all cases. $^{22} 242627$

The remaining 12 studies used talc to treat both patients with PSP and SSP (table 3). One RCT estimated a reduction in recurrence rates by performing talc pleurodesis via chest drain compared with drainage alone, OR 0.16 (95\% CI 0.03 to 0.85 ). ${ }^{6}$ Two small studies insufflated talc under local anaesthetic and reported $0 \%$ recurrence in 24 patients $^{30}$ and 20 patients, ${ }^{31}$ respectively. However, four larger series including 521 patients undergoing talc poudrage at thoracoscopy found recurrence rates of $5.6-16.1 \%$ (including early failures). ${ }^{32-35}$ One study comparing talc to autologous blood pleurodesis found lower recurrence in the talc group (OR 0.48 ) but wide CIs $(0.10$ to 2.24). ${ }^{36}$ A retrospective case series of 122 patients using talc pleurodesis via chest drain found a similar recurrence rate of $13.3 \% .{ }^{37}$ A further three retrospective surgical studies, including 317 patients undergoing VATS bullectomy and talc poudrage for PSP and SSP, found recurrence rates of $1.1-4.5 \% .^{38-40}$ The (non-randomised) comparator groups of the two studies $(n=312)$ found the recurrence rate for talc via chest drain for SSP to be $2.9 \%{ }^{38}$ and $30.8 \% .^{40}$ Although the difference in the latter study was statistically significant, the two patient groups were very different: patients receiving talc via chest drain were those not deemed fit for VATS. ${ }^{40}$

\section{Tetracycline}

Eleven studies evaluated the efficacy of tetracycline pleurodesis for SP via chest drains or thoracoscopy without intervention on the lung (table 4). These were of variable quality including both PSP and SSP but comprised three RCTs including a total of 366 patients. Two RCTs, from 1990 and 1989, randomised patients 


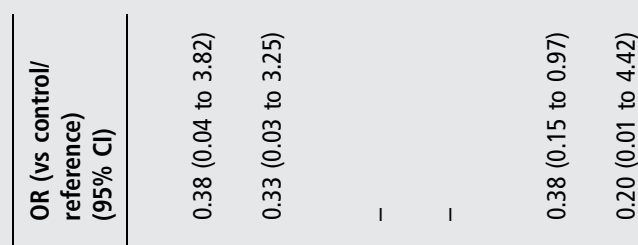



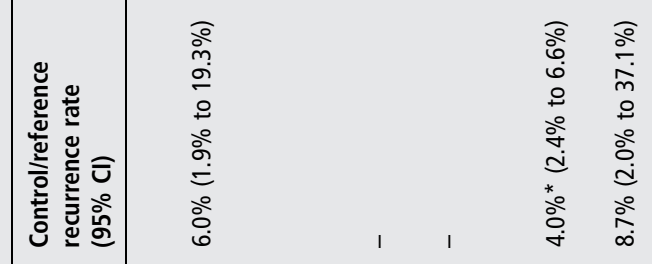

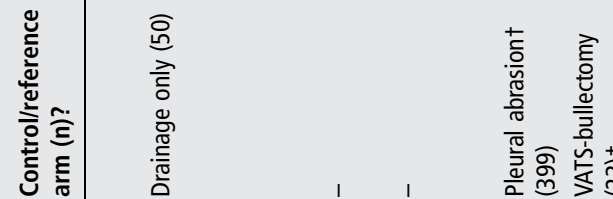



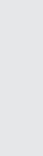

厗



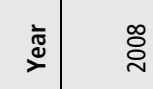



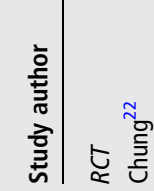

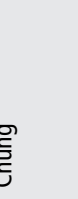

1

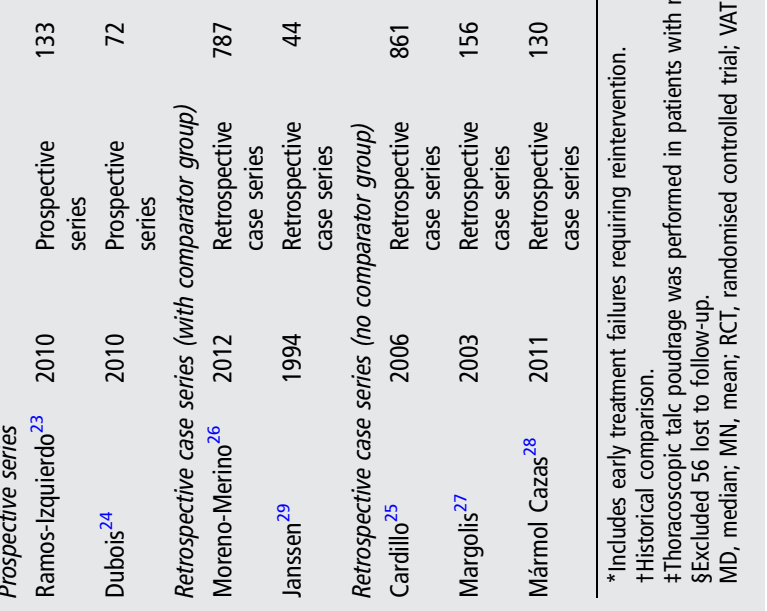




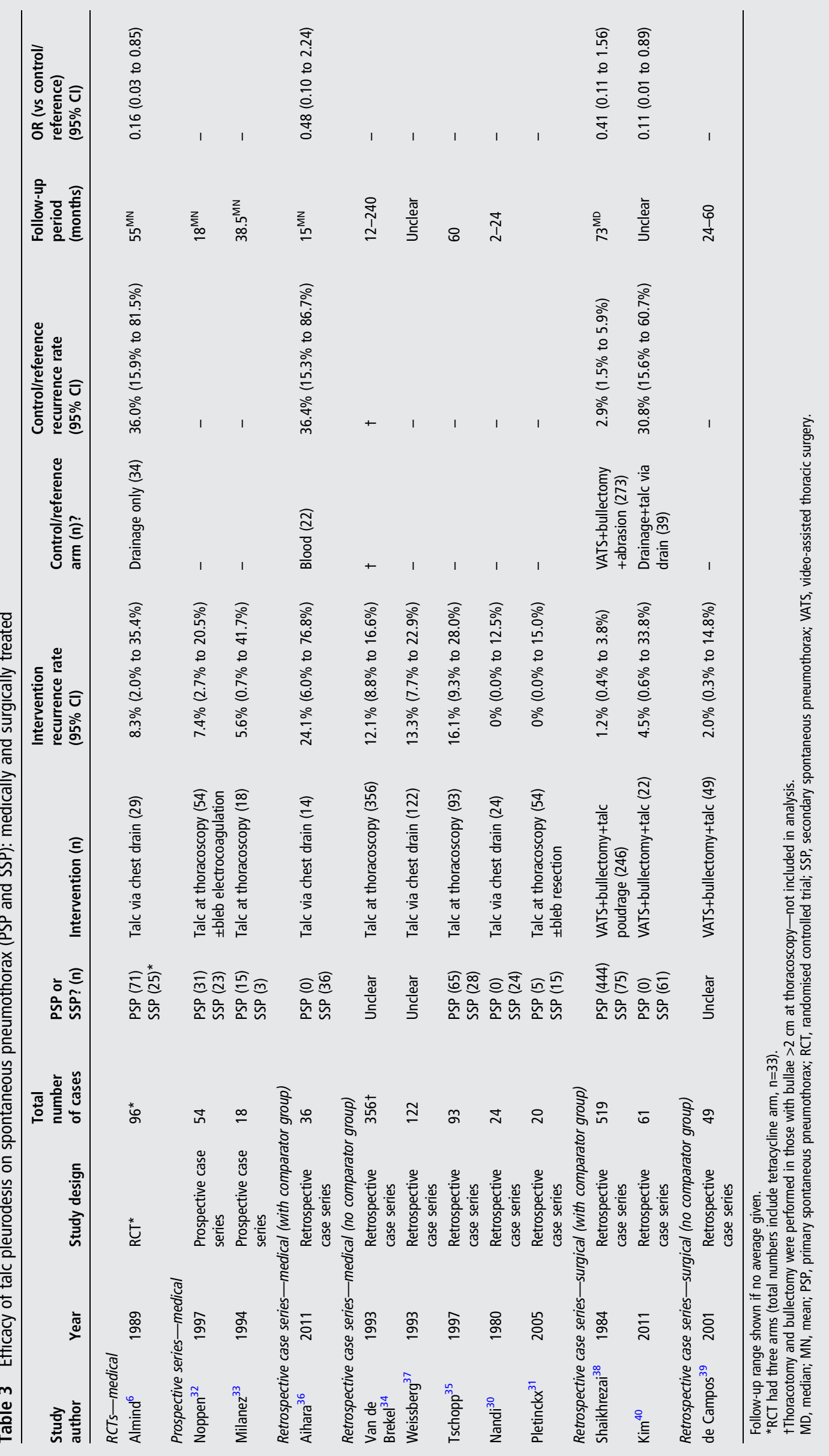




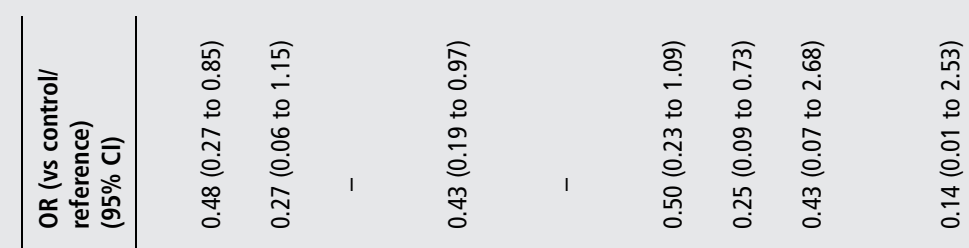

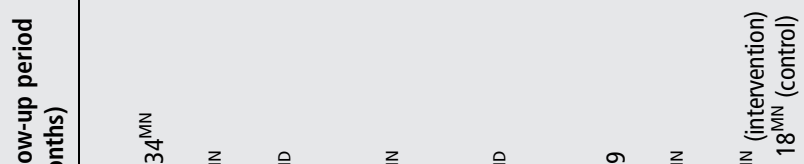

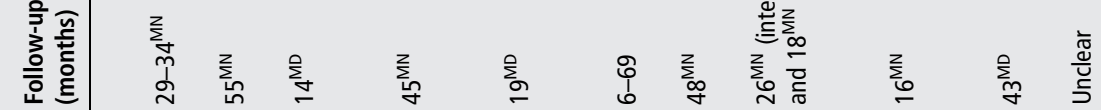

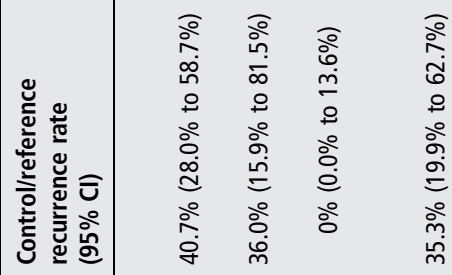

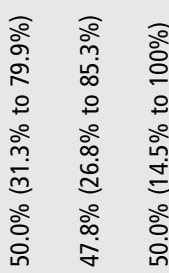

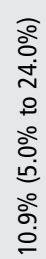

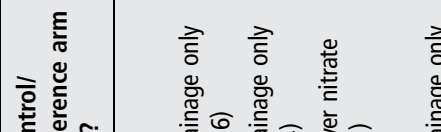

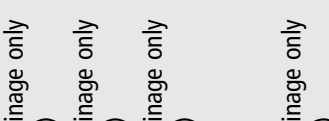

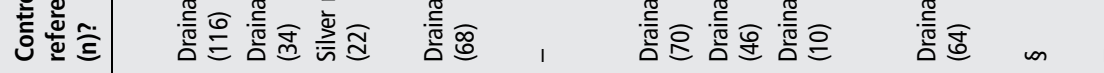

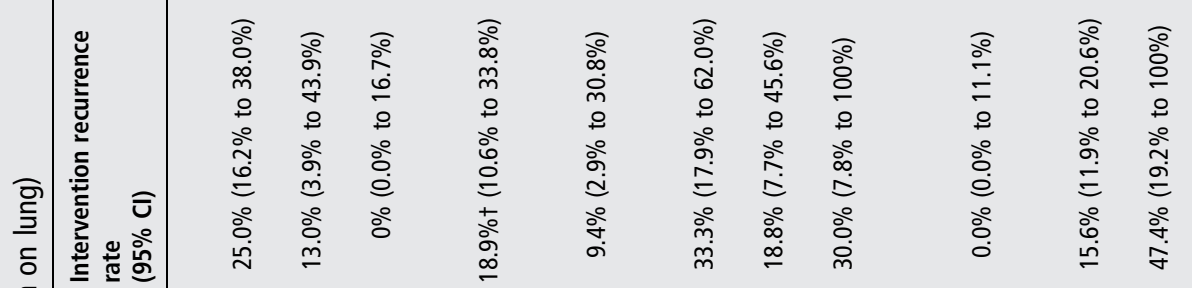

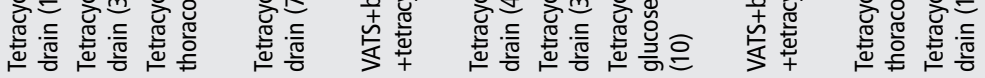

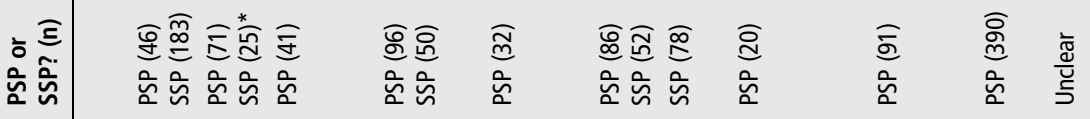

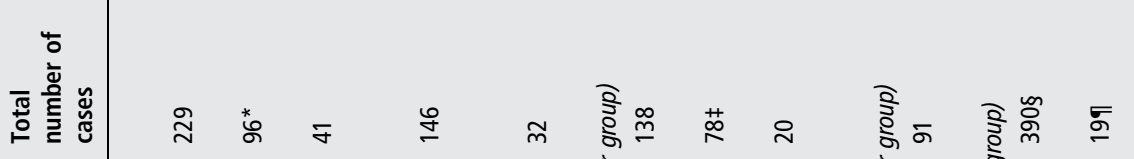

$\frac{5}{\frac{5}{4}}$

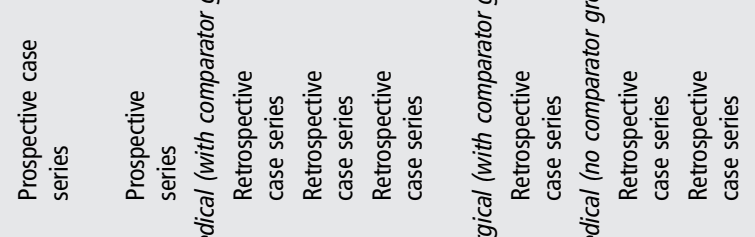
홓

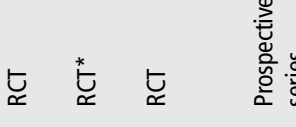
๖ ๖

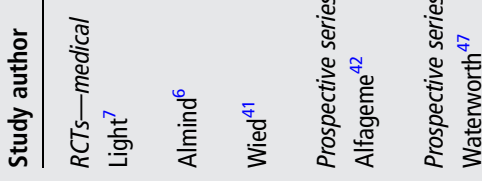
M las gis

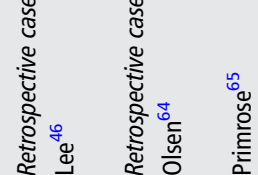


to either tetracycline versus chest drain or drainage only. ${ }^{6} 7$ Both reported lower rates in the tetracycline arm but only one study was statistically significant, OR 0.48 (95\% CI 0.27 to $0.85){ }^{7}$ The other small RCT of tetracycline versus silver nitrate at thoracoscopy found recurrence rate of $0 \%$ in both arms. ${ }^{41}$ Four non-randomised retrospective studies of tetracycline versus drainage alone all estimated reduced recurrence rates in the tetracycline group. However, all but one had wide CIs crossing the null value of 1: OR 0.50 (95\% CI 0.23 to 1.09 ), 0.25 (95\% CI 0.09 to 0.73 ), 0.43 (95\% CI 0.07 to 2.68$)$ and 0.14 (95\% CI 0.01 to 2.53$).^{42-45}$ It should be noted that four studies included only patients with first occurrence of SP, ${ }^{64} 4345$ with the remaining seven studies not specifying indication for recurrence prevention. One surgical study of tetracycline after VATS bullectomy reported no recurrences $(0.0 \%)$ in contrast to $10.9 \%$ in a group treated non-surgically with chest tube drainage alone. ${ }^{46}$ However, another older prospective surgical series showed a recurrence rate of $9.4 \%$ with no control group. ${ }^{47}$

\section{Blood}

Five studies of blood patch pleurodesis were included in the analysis $(n=270$, table 5). There were no RCTs compared with drainage alone. Two studies prospectively enrolled patients after SP with persistent air leak. One non-randomised study estimated an OR of 0.47 (95\% CI 0.17 to 1.32 ) for recurrence in patients following autologous blood pleurodesis compared with drainage alone $(15.6 \%$ blood pleurodesis, including early failures requiring surgery, vs $28.1 \%$ drainage). ${ }^{48}$

As noted in the 'Talc' section above, a small retrospective comparison study of talc via chest drain versus blood patch was inconclusive. ${ }^{39}$ Two further small retrospective series of patients unfit for surgery with recurrence or persistent air leak found long-term recurrence of $16.0 \%{ }^{49}$ and $16.1 \%{ }^{50}$ with no comparator groups.

\section{Minocycline}

Three RCTs in patients with PSP $(n=498)$ found recurrence rates of $0 \%{ }^{17}$ and $1.9 \%$ after the instillation of minocycline after lung re-expansion post-VATS procedure ${ }^{51}$ but $29.2 \%$ after instillation via chest drain only (ie, medical management, no intervention on the lung) in patients with first presentations of PSP $^{52}$ (table 6). This RCT provided evidence of a reduction in recurrence compared with drainage only in non-surgical patients (minocycline $29.2 \%$ vs drainage only $49.1 \%$, OR 0.43 , 95\% CI 0.24 to 0.75$).{ }^{52}$ Among surgical patients, Chen et $a l^{51}$ also observed a reduced recurrence rate compared with patients receiving saline, but the strength of statistical evidence was weak (minocycline $1.9 \%$ vs saline $8.1 \%$, OR 0.23 , 95\% CI 0.05 to 1.09). The third surgical RCT, comparing minocycline versus mechanical abrasion, was small and inconclusive (minocycline $0.0 \%$ vs mechanical abrasion $5.0 \%$, OR 0.18 , 95\% CI 0.01 to 3.89). ${ }^{17}$

There were also two retrospective non-randomised studies with control arms. One suggested that minocycline significantly reduced recurrence rates with minocycline post-VATS compared with saline (minocycline $2.9 \%$ vs $9.8 \%$ saline, OR $0.27,95 \%$ CI 0.09 to 0.85 ) in a historical comparison. ${ }^{53}$ The other comparative study in patients with prolonged air leak post-VATS for SP found increased recurrence rates in the minocycline group compared with OK-432 (estimated failure rate $36.7 \%$ minocycline vs 5.3\% OK-432, OR 10.42, 95\% CI 1.30 to 83.5$).{ }^{54}$

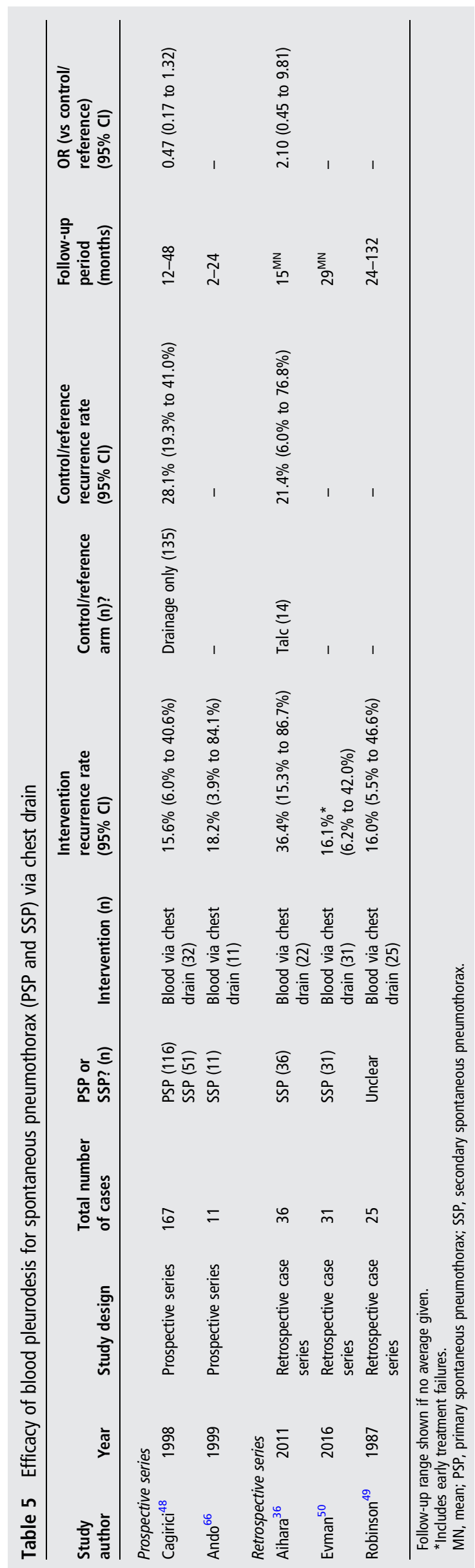






Other agents

A retrospective surgical series of 81 cases reported a recurrence rate of $6.2 \%$ when using iodopovidone during VATS despite only $37 \%$ undergoing bullae resection. Two small studies in India assessed the efficacy of iodopovidone via chest drain. One randomised trial $(n=35)$ had no recurrence in either the iodopovidone or talc pleurodesis arms $\mathrm{s}^{55}$ and a retrospective review of 27 cases found a recurrence rate of $7.4 \% .^{56}$

Two studies used silver nitrate as a chemical pleurodesis agent: one RCT (see table 4) reported $0 \%$ recurrence after instillation at thoracoscopy but described increased pleural fluid production and longer hospital stay than using tetracycline. ${ }^{41} \mathrm{~A}$ retrospective surgical study ( $\mathrm{n}=184,3$ years follow-up) used silver nitrate after VATS bullectomy with a recurrence rate of $1.1 \%$, but had no comparison group. ${ }^{57} \mathrm{~A}$ retrospective series reviewing recurrence prevention at first occurrence found a significant recurrence rate using gentamicin via chest drain, although this was more efficacious than drainage alone (3-year recurrence rates $26.1 \%$ and $50.0 \%$, respectively (OR $0.35,95 \%$ CI 0.12 to 1.00 , with a reported $\mathrm{p}$ value $<0.05) .{ }^{43} \mathrm{~A}$ small study including 17 spontaneous pneumothoraces found only one recurrence (5.9\%) after administration of quinacrine. ${ }^{58}$ In a group of 57 patients with SSP deemed too high risk for surgery with ongoing air leak, fibrin glue (diluted fourfold) was instilled via chest drain. The long-term (60 months) recurrence rate was $10.5 \% .^{59}$ The addition of acromycin post-VATS bullectomy reportedly reduced recurrence to $3.8 \%$ from $20.0 \%$, in a nonrandomised historical comparison group, but CIs were wide (OR $0.16,95 \%$ CI 0.02 to 1.48 ), despite the authors stating a p value $<0.05 .^{60}$

\section{DISCUSSION}

This is the first study to our knowledge to systematically review the evidence for the effectiveness of pleurodesis in recurrence prevention for all chemical pleurodesis agents in cases of SP in both 'medical' pleurodesis (ie, no intervention on the lung) and as an adjunct to surgical procedures. Patients with postoperative surgical air leak were specifically excluded as patients having undergone thoracic surgery (eg, for wedge resection or lobectomy) with subsequent air leak are likely to be a different population from those with spontaneous pneumothoraces. For the same reason, unlike previous reviews of pleurodesis efficacy, patients undergoing pleurodesis for malignant pleural effusion recurrence prevention were excluded.

Given the considerable heterogeneity across studies in design, outcomes and interventions, formal data synthesis via metaanalysis was not conducted as we do not believe the results would be clinically meaningful. Only 9 of 50 studies were RCTs. Also, 13 of the 41 other studies (case series) provided comparator groups but these were historical comparisons or non-randomised comparator groups. The lack of head-to-head comparisons limits the ability to formally compare relative effectiveness of different agents in this review. This is in contrast to a recent Cochrane review of pleurodesis agents in malignant pleural effusion, in which a network meta-analysis of pleurodesis agents was possible with 62 RCTs identified. ${ }^{61}$

Studies in which the control arms were drainage with a chest drain only (ie, no other agent) suggest recurrence rates of 26.1-50.1\%. Talc pleurodesis would appear to be effective at reducing recurrence for PSP when used via poudrage at thoracoscopy, with two studies with comparator arms giving recurrence rates of $5.1 \%$ and $2.6 \%$ with OR $0.10(95 \%$ CI 0.03 to 0.38$)$ and 0.08 (95\% CI 0.01 to 0.69 ), respectively, when comparing talc 
poudrage to drainage alone. ${ }^{18} 19$ However, more recent case series data suggested higher recurrence rates $\left(9.5 \%{ }^{20}\right.$ and $\left.10.2 \%\right) .{ }^{21}$

When talc is used in patients undergoing surgical (VATS) procedures, the recurrence rate appears to be low (between $0.0 \%$ and 3.2\%) and it seems that the addition of talc contributes to a lower recurrence compared with VATS bullectomy and either drainage or abrasion alone. There have been no direct comparisons of VATS bullectomy and pleurectomy to VATS bullectomy and talc pleurodesis. Results for talc poudrage at thoracoscopy (without interventional on the lung) in the general SP (PSP and SSP) appear to be between $5.6 \%$ and $16.1 \%$ in larger case series (without comparator arms). No studies of talc slurry pleurodesis for SP alone were found, except two studies with small comparator groups of 14 and 10 patients, which gave $21.4 \%$ and $0.0 \%$ recurrence rates, respectively. ${ }^{36}{ }^{55} \mathrm{~A}$ previous systematic review of talc pleurodesis of 22 studies in 1994 found an overall success rate of 91\%; however, 6 of 15 studies assessing talc poudrage and the 4 studies assessing talc slurry were small ( $\leq 10$ patients) such that estimated rates are very imprecise. ${ }^{62}$

The majority of studies assessing the reduction in recurrence rate by 'medical' pleurodesis agents via chest drain involve tetracycline. The higher-quality studies (RCTs) would suggest a recurrent rate of between $13 \%$ and $25 \%$, which is significantly better than those receiving drainage only (OR $0.27,95 \%$ CI 0.06 to 1.15 , and 0.61 with $0.48,95 \%$ CI 0.27 to 0.85$).^{6} 7$ Blood patch pleurodesis for persistent air leak in those patients not fit for surgery seems to deliver a recurrence rate of around $16 \% .{ }^{49}{ }^{50}$ An RCT assessing the short-term efficacy of autologous blood patch pleurodesis at varying doses found that administration of 1 or $2 \mathrm{~mL} / \mathrm{kg}$ was more successful at ceasing air leak by 13 days (both $82 \%)$ than $0.5 \mathrm{~mL} / \mathrm{kg}$ or saline $(27 \%$ and $9 \%$, respectively). ${ }^{63}$

Minocycline appears to be the agent of choice in Taiwan. Instillation of talc via chest drain once the lung has re-expanded post-VATS bullectomy results in a low recurrence rate. ${ }^{7} 5153$ Minocycline via chest drain without surgical intervention in patients with first presentation of PSP also seems to provide a significant reduction in recurrence, ${ }^{52}$ although its use is not commonplace.

There are numerous other pleurodesis agents with potential efficacy. Iodopovidone is widely available in India with one small RCT demonstrating equivalent success rates to talc. ${ }^{55}$ The case for widespread use of acromycin, gentamycin or quinacrine via chest drains, and silver nitrate or diluted fibrin glue post-VATS is still to be made.

These results are consistent with recent network meta-analysis of pleurodesis for malignant pleural effusions, which found that talc poudrage was highly effective, followed by talc slurry, mepacrine, iodine, bleomycin and doxycycline, although this is clearly a different patient population. ${ }^{6}$

The indication for pleurodesis in the vast majority of studies was ongoing air leak or recurrence prevention at second occurrence as per guideline recommendation. However, one study assessed early surgical intervention at first occurrence. ${ }^{27}$ This group was controversially managed without aspiration or chest tube drainage, undergoing VATS with bleb resection and talc poudrage pleurodesis within 12 hours of first presentation. While none of these patients had a subsequent recurrence, it is likely that a significant proportion were unnecessarily operated upon as many may have resolved with conservative management and not recurred.

There are a number of limitations to this systematic review. First, our review is limited by the quality of the available data. Although we identified a few well-conducted RCTs, the majority of identified studies were observational, many of which were non-comparative. Many included studies were also retrospective, with a high risk of reporting bias. Thirteen papers published pre-1995 in foreign (non-English) language and not available in print were not included. Indications for pleurodesis varied across the studies including those solely assessing patients at first occurrence, those with recurrent pneumothorax or air leak patients, and those with ongoing air leak only. Size of pneumothorax at presentation and details of previous treatment were not always provided. There was variation both within and across surgical studies as to the specific co-incident procedure being undertaken (alongside chemical pleurodesis). The exact procedure was often determined on visual inspection of the lung (eg, bleb/bullae resection or electrocoagulation only performed if visible blebs and bullae seen) but results usually only reported as overall recurrence rates. This results in significant clinical heterogeneity in the published data, and therefore interpretation of results across study types should be guarded.

\section{CONCLUSION}

This comprehensive systematic review of the literature demonstrates that numerous agents have been used for chemical pleurodesis for recurrence prevention in SP. Chemical pleurodesis alongside surgical treatment or via thoracoscopy appears most effective in preventing recurrence, but is not suitable for all patients. Evidence for relative success rates between agents is limited by the small number of randomised and prospective comparative trials. Well-controlled and conducted RCTs are now required using a number of candidate agents to assess optimal management in SP recurrence prevention and treatment.

Twitter Follow Hayley Jones at @hayley0110

Acknowledgements The authors thank Elinor Harriss from Bodleian Health Care Libraries (University of Oxford) for her invaluable assistance with literature searches and article recovery.

Contributors All authors included on a paper fulfil the criteria of authorship. RJH, $A Y, J P C, I P$ and NMR were involved in project conception, drafting and final approval of the manuscript. RJH and AY conducted abstract review and data analysis. HEJ reviewed methodology, analysis and presentation of the results. Elinor Harriss (Bodleian Health Care Libraries, University of Oxford) assisted with literature searches and article recovery. RJH is the guarantor.

Competing interests RJH is funded by a Clinical Training Fellowship from the Medical Research Council (MR/L017091/1).

Provenance and peer review Not commissioned; externally peer reviewed.

Data sharing statement The corresponding author (RH) holds the data analysis. No unpublished data exist.

Open Access This is an Open Access article distributed in accordance with the terms of the Creative Commons Attribution (CC BY 4.0) license, which permits others to distribute, remix, adapt and build upon this work, for commercial use, provided the original work is properly cited. See: http://creativecommons.org/licenses/ by/4.0/

\section{REFERENCES}

1 Melton LJ, Hepper NGG, Offord KP. Incidence of spontaneous pneumothorax in Olmsted County, Minnesota: 1950 to 1974. Am Rev Respir Dis 1979;102:1379-82.

2 Bense L, Eklund G, Wiman LG. Smoking and the increased risk of contracting spontaneous pneumothorax. Chest 1987;92:1009-12.

3 Gupta D, Hansell A, Nichols T, et al. Epidemiology of pneumothorax in England. Thorax 2000;55:666-71.

4 Bobbio A, Dechartres A, Bouam S, et al. Epidemiology of spontaneous pneumothorax: gender-related differences. Thorax 2015;70:653-8.

5 Ruckley CV, McCormack RJM. The management of spontaneous pneumothorax. Thorax 1966;21:139-44

6 Almind M, Lange P, Viskum K. Spontaneous pneumothorax: comparison of simple drainage, talc pleurodesis, and tetracycline pleurodesis. Thorax 1989;44:627-30.

7 Light RW, O'Hara VS, Moritz TE, et al. Intrapleural tetracycline for the prevention of recurrent spontaneous pneumothorax. Results of a Department of Veterans Affairs cooperative study. JAMA 1990;264:2224-30. 
8 Lippert HL, Lund $\mathrm{O}$, Blegvad $\mathrm{S}$, et al. Independent risk factors for cumulative recurrence rate after first spontaneous pneumothorax. Eur Respir J 1991;4:324-31.

9 Harvey J, Prescott RJ. Simple aspiration versus intercostal tube drainage for spontaneous pneumothorax in patients with normal lungs. British Thoracic Society Research Committee. BMJ 1994;309:1338-9.

10 Andrivet P, Djedaini K, Teboul JL, et al. Spontaneous pneumothorax. Comparison of thoracic drainage vs immediate or delayed needle aspiration. Chest 1995;108:335-9.

110 'Rourke JP, Yee ES. Civilian spontaneous pneumothorax. Treatment options and long-term results. Chest 1989;96:1302-6.

12 Seremetis MG. The Management of Spontaneous Pneumothorax. Chest 1970;57:65-8.

13 Baumann MH, Strange C, Heffner JE, et al., AACP Pneumothorax Consensus Group. Management of spontaneous pneumothorax: an American College of Chest Physicians Delphi consensus statement. Chest 2001;119:590-602.

14 MacDuff A, Arnold A, Harvey J. Management of spontaneous pneumothorax: British Thoracic Society Pleural Disease Guideline 2010. Thorax 2010;65(Suppl 2):ii18-31.

15 De Leyn P, Lismonde M, Ninane V, et al. Guidelines Belgian Society of Pneumology. Guidelines on the management of spontaneous pneumothorax. Acta Chir Belg 2005:105:265-7

16 Higgins JPT, Green S, eds. Cochrane Handbook for Systematic Reviews of Interventions Version 5.1.0 (updated March 2011). The Cochrane Collaboration, 2011.

17 Alayouty HD, Hasan TM, Alhadad ZA, et al. Mechanical versus chemical pleurodesis for management of primary spontaneous pneumothorax evaluated with thoracic echography. Interact Cardiovasc Thorac Surg 2011;13:475-9.

18 Tschopp JM, Boutin C, Astoul P, et al. Talcage by medical thoracoscopy for primary spontaneous pneumothorax is more cost-effective than drainage: a randomised study. Eur Respir J 2002:20:1003-9.

19 Verschoof AC, Ten Velde GP, Greve LH, et al. Thoracoscopic pleurodesis in the management of spontaneous pneumothorax. Respiration 1988:53:197-200.

20 Györik S, Erni S, Studler U, et al. Long-term follow-up of thoracoscopic talc pleurodesis for primary spontaneous pneumothorax. Eur Respir J 2007;29:757-60.

21 Adewole 00, De Keukeleire T, Phillips AS, et al. Effectiveness of thoracoscopic talc pleurodesis in the management of complicated spontaneous pneumothorax. J Bronchology Interv Pulmonol 2015;22:48-51.

22 Chung WJ, Jo WM, Lee SH, et al. Effects of additional pleurodesis with dextrose and talc-dextrose solution after video assisted thoracoscopic procedures for primary spontaneous pneumothorax. J Korean Med Sci 2008;23:284-7.

23 Ramos-Izquierdo R, Moya J, Macia I, et al. Treatment of primary spontaneous pneumothorax by videothoracoscopic talc pleurodesis under local anesthesia: a review of 133 procedures. Surg Endosc 2010;24:984-7.

24 Dubois L, Malthaner RA. Video-assisted thoracoscopic bullectomy and talc poudrage for spontaneous pneumothoraces: effect on short-term lung function. I Thorac Cardiovasc Surg 2010;140:1272-5.

25 Cardillo G, Carleo F, Giunti R, et al. Videothoracoscopic talc poudrage in primary spontaneous pneumothorax: a single-institution experience in 861 cases. J Thorac Cardiovasc Surg 2006;131:322-8.

26 Moreno-Merino S, Congregado M, Gallardo G, et al. Comparative study of talc poudrage versus pleural abrasion for the treatment of primary spontaneous pneumothorax. Interact Cardiovasc Thorac Surg 2012:15:81-5.

27 Margolis M, Gharagozloo F, Tempesta B, et al. Video-assisted thoracic surgical treatment of initial spontaneous pneumothorax in young patients. Ann Thorac Surg 2003;76:1661-3

28 Mármol Cazas EE, Martínez Somolinos S, Baldó Padró X, et al. [Efficacy, morbidity and mortality of surgical treatment of a primary spontaneous pneumothorax by videothorascopic talc pleurodesis]. Cir Esp 2011;89:463-7.

29 Janssen JP, van Mourik J, Cuesta Valentin M, et al. Treatment of patients with spontaneous pneumothorax during videothoracoscopy. Eur Respir J 1994;7:1281-4.

30 Nandi P. Recurrent spontaneous pneumothorax; an effective method of talc poudrage. Chest 1980;77:493-5.

31 Pletinckx P, Muysoms F, De Decker $C$, et al. Thoracoscopic talc pleurodesis for the treatment of spontaneous pneumothorax. Acta Chir Belg 2005;105:504-7.

32 Noppen M, Meysman M, d'Haese J, et al. Comparison of video-assisted thoracoscopic talcage for recurrent primary versus persistent secondary spontaneous pneumothorax. Eur Respir J 1997;10:412-16.

33 Milanez JR, Vargas FS, Filomeno LT, et al. Intrapleural talc for the prevention of recurrent pneumothorax. Chest 1994;106:1162-5.

34 van de Brekel JA, Duurkens VA, Vanderschueren RG. Pneumothorax. Results of thoracoscopy and pleurodesis with talc poudrage and thoracotomy. Chest 1993:103:345-7.

35 Tschopp JM, Brutsche M, Frey JG. Treatment of complicated spontaneous pneumothorax by simple talc pleurodesis under thoracoscopy and local anaesthesia. Thorax 1997;52:329-32.

36 Aihara K, Handa T, Nagai S, et al. Efficacy of blood-patch pleurodesis for secondary spontaneous pneumothorax in interstitial lung disease. Intern Med 2011;50:1157-62.

37 Weissberg D, Ben-Zeev I. Talc pleurodesis. Experience with 360 patients. J Thorac Cardiovasc Surg 1993;106:689-95.
38 Shaikhrezai K, Thompson Al, Parkin C, et al. Video-assisted thoracoscopic surgery management of spontaneous pneumothorax--long-term results. Eur I Cardiothorac Surg 2011;40:120-3.

39 de Campos JR, Vargas FS, de Campos Werebe E, et al. Thoracoscopy talc poudrage: a 15-year experience. Chest 2001;119:801-6.

40 Kim SJ, Lee HS, Kim HS, et al. Outcome of video-assisted thoracoscopic surgery for spontaneous secondary pneumothorax. Korean I Thorac Cardiovasc Surg 2011;44:225-8.

41 Wied U, Halkier E, Hoeier-Madsen K, et al. Tetracycline versus silver nitrate pleurodesis in spontaneous pneumothorax. J Thorac Cardiovasc Surg 1983;86:591-3.

42 Alfageme I, Moreno L, Huertas C, et al. Spontaneous pneumothorax. Long-term results with tetracycline pleurodesis. Chest 1994;106:347-50.

43 Guo Y, Xie C, Rodriguez RM, et al. Factors related to recurrence of spontaneous pneumothorax. Respirology 2005;10:378-84.

44 Tanaka F, Itoh M, Esaki H, et al. Secondary spontaneous pneumothorax. Ann Thorac Surg 1993;55:372-6.

45 van den Brande P, Staelens I. Chemical pleurodesis in primary spontaneous pneumothorax. Thorac Cardiovasc Surg 1989:37:180-2.

46 Lee HW, Lee Jl, Kim KW, et al. The effects of additional tetracycline pleurodesis during thoracoscopic procedures for treating primary spontaneous pneumothorax. Korean I Thorac Cardiovasc Surg 2008;41:729-35.

47 Waterworth PD, Kallis P, Townsend ER, et al. Thoracoscopic bullectomy and tetracycline pleurodesis for the treatment of spontaneous pneumothorax. Respir Med 1995;89:563-6.

48 Cagirici U, Sahin B, Cakan A, et al. Autologous blood patch pleurodesis in spontaneous pneumothorax with persistent air leak. Scand Cardiovasc J 1998;32:75-8.

49 Robinson CL. Autologous blood for pleurodesis in recurrent and chronic spontaneous pneumothorax. Can J Surg 1987;30:428-9.

50 Evman S, Alpay L, Metin S, et al. The efficacy and economical benefits of blood patch pleurodesis in secondary spontaneous pneumothorax patients. Kardiochir Torakochirurgia Pol 2016;13:21-5.

51 Chen JS, Hsu HH, Chen RJ, et al. Additional minocycline pleurodesis after thoracoscopic surgery for primary spontaneous pneumothorax. Am J Respir Crit Care Med 2006; 173:548-54.

52 Chen JS, Chan WK, Tsai KT, et al. Simple aspiration and drainage and intrapleural minocycline pleurodesis versus simple aspiration and drainage for the initial treatment of primary spontaneous pneumothorax: an open-label, parallel-group, prospective, randomised, controlled trial. Lancet 2013;381:1277-82.

53 Chen JS, Hsu HH, Kuo SW, et al. Effects of additional minocycline pleurodesis after thoracoscopic procedures for primary spontaneous pneumothorax. Chest 2004;125:50-5

54 How CH, Tsai TM, Kuo SW, et al. Chemical pleurodesis for prolonged postoperative air leak in primary spontaneous pneumothorax. J Formos Med Assoc 2014;113:284-90.

55 Agarwal R, Paul AS, Aggarwal AN, et al. A randomized controlled trial of the efficacy of cosmetic talc compared with iodopovidone for chemical pleurodesis. Respirology 2011;16:1064-9.

56 Agarwal R, Aggarwal AN, Gupta D, et al. Efficacy and safety of iodopovidone in chemical pleurodesis: a meta-analysis of observational studies. Respir Med 2006;100:2043-7.

57 Marcheix B, Brouchet L, Renaud C, et al. Videothoracoscopic silver nitrate pleurodesis for primary spontaneous pneumothorax: an alternative to pleurectomy and pleural abrasion? Eur I Cardiothorac Surg 2007;31:1106-9.

58 Janzing HM, Derom A, Derom E, et al. Intrapleural quinacrine instillation for recurrent pneumothorax or persistent air leak. Ann Thorac Surg 1993;55:368-71.

59 Kinoshita T, Miyoshi S, Suzuma T, et al. Intrapleural administration of a large amount of diluted fibrin glue for intractable pneumothorax. A clinical study based on 57 cases: including 2 unsuccessful cases. Jpn I Thorac Cardiovasc Surg 2003:51:41-7.

60 Loubani M, Lynch V. Video assisted thoracoscopic bullectomy and acromycin pleurodesis: an effective treatment for spontaneous pneumothorax. Respir Med 2000;94:888-90

61 Clive $A O$, Jones $H E$, Bhatnagar $R$, et al. Interventions for the management of malignant pleural effusions: a network meta-analysis. Cochrane Database Syst Rev 2016:5:CD010529.

62 Kennedy L, Sahn SA. Talc pleurodesis for the treatment of pneumothorax and pleural effusion. Chest 1994;106:1215-22.

63 Cao Gq, Kang J, Wang F, et al. Intrapleural instillation of autologous blood for persistent air leak in spontaneous pneumothorax in patients with advanced chronic obstructive pulmonary disease. Ann Thorac Surg 2012;93:1652-7.

64 Olsen PS, Andersen HO. Long-term results after tetracycline pleurodesis in spontaneous pneumothorax. Ann Thorac Surg 1992;53:1015-17.

65 Primrose WR. Spontaneous pneumothorax: a retrospective review of aetiology, pathogenesis and management. Scott Med J 1984;29:15-20.

66 Ando M, Yamamoto M, Kitagawa C, et al. Autologous blood-patch pleurodesis for secondary spontaneous pneumothorax with persistent air leak. Respir Med 1999;93:432-4 